\title{
ROOM-TEMPERATURE LINAC STRUCTURES FOR THE SPALLATION NEUTRON SOURCE*
}

\author{
J. H. Billen, L. M. Young, S. Kurennoy, Los Alamos National Laboratory, \\ K. R. Crandall, TechSource
}

\begin{abstract}
Los Alamos National Laboratory is building roomtemperature $\mathrm{rf}$ accelerating structures for the Spallation Neutron Source (SNS). These structures, for $\mathrm{H}^{-}$ions, consist of six 402.5-MHz, 2-MW drift-tube linac (DTL) tanks from 2.5 to $87 \mathrm{MeV}$ followed by four $805-\mathrm{MHz}, 4-$ MW coupled-cavity linac (CCL) modules to $186 \mathrm{MeV}$. The DTL uses permanent magnet quadrupoles inside the drift tubes arranged in a $6 \beta \lambda$ FFODDO lattice with every third drift tube available for diagnostics and steering. The CCL uses a $13 \beta \lambda$ FODO electromagnetic quadrupole lattice. Diagnostics and magnets occupy the $2.5 \beta \lambda$ spaces between 8 -cavity segments. This paper discusses design of the rf cavities and low-power modeling work.
\end{abstract}

\section{INTRODUCTION}

A previous paper [1], described the baseline design for a room-temperature $1-\mathrm{GeV}$ linac that would deliver to the accumulator ring 1.1 MW of average power. In 2000, baseline changes eliminated the upgrade option to 4.4 MW and replaced a substantial part of the CCL with superconducting cavities.

Without the 4-MW upgrade option, beam funneling at $20 \mathrm{MeV}$ is not needed. A funnel required doubling the $\mathrm{rf}$ frequency at relatively low particle velocity and was facilitated by a coupled-cavity drift-tube linac (CCDTL) structure, which has higher efficiency than a conventional CCL for $\beta<0.4$. To simplify the design, we eliminated the $805-\mathrm{MHz}$ CCDTL and extended the $402.5-\mathrm{MHz}$ DTL to higher energy. The $805-\mathrm{MHz} \mathrm{CCL}$ starts at $87 \mathrm{MeV}$ and ends at the $186-\mathrm{MeV}$ transition to superconducting elliptical cavities. Reference 1 discussed DTL and CCL cell-design procedures for achieving maximum efficiency with peak surface electric fields below 1.3 Kilpatrick. The same procedures apply to the present design.

\section{DRIFT-TUBE LINAC}

The original one-tank, 20-MeV DTL had a $4 \beta \lambda$ long transverse focusing lattice with permanent magnet quadrupoles (PMQs) inside every drift tube. The new design has 6 tanks and a longer transverse period. The PMQs are arranged in a FFODDO lattice of length $6 \beta \lambda$. This change in the focusing lattice has two advantages: 1) the period lengths in the DTL nearly matches that of the following CCL, and 2) every third drift tube is available

*Work supported by the Office of Energy Research, Basic Energy Science of the US Department of Energy, and by Oak Ridge National Laboratory. for either beam-position monitors (BPMs) or dipole steering magnets. In each tank, we will install BPMs near the tank entrance and bipolar electromagnetic dipole magnets near the tank exit.

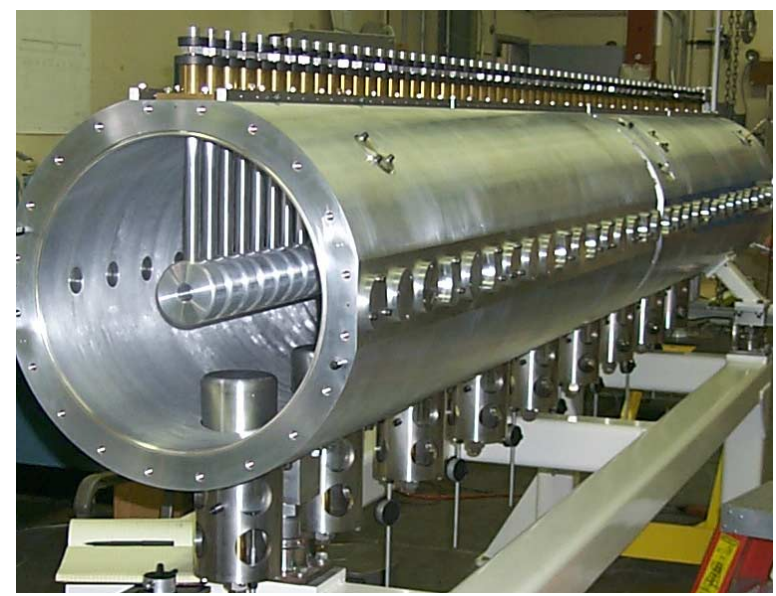

Figure 1. Full scale aluminum model of DTL tank 1.

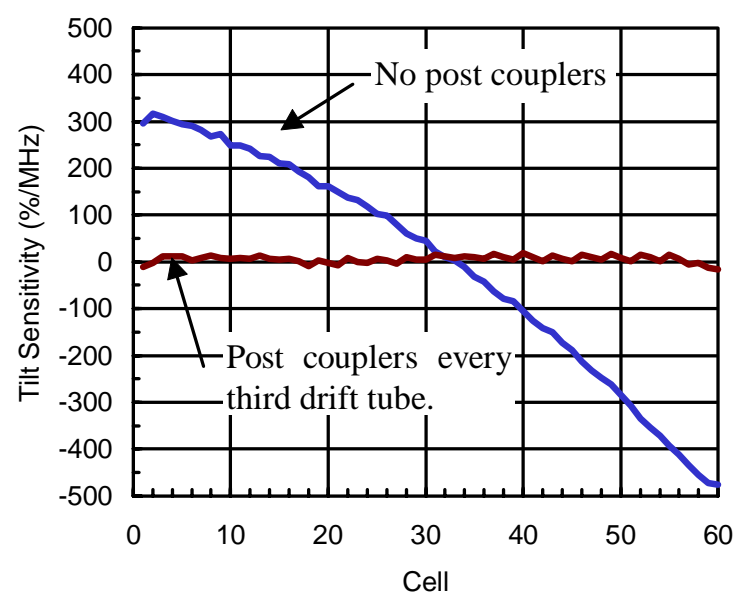

Figure 2. Tilt sensitivity with 19 post couplers.

Figure 1 shows the full scale aluminum model of DTL tank 1, built from production-model drawings with highpower features removed. The production tanks are $\sim 2-\mathrm{m}-$ long copper-plated steel sections bolted together. Tanks 2 through 6 have three sections each and tank 1 has two sections. Each tank section includes 4 water-cooled slug tuners visible along the tank bottom in Fig. 1. The total tuning range is $2 \mathrm{MHz}$. During low-power tuning we will determine the size of these tuners and then machine and install fixed copper slugs of the required length. The lowlevel rf control system varies the water coolant temperature to maintain the cavity on resonance. 
Table 1. SNS DTL Design Summary

\begin{tabular}{|c|c|c|c|c|c|c|c|c|c|c|c|c|}
\hline Tank & $\begin{array}{c}\text { Drift } \\
\text { tubes }\end{array}$ & PMQs & $\begin{array}{c}\text { Post } \\
\text { couplers }\end{array}$ & $\begin{array}{c}\text { Length } \\
(\mathrm{m})\end{array}$ & $\begin{array}{c}\text { Diam. } \\
(\mathrm{cm})\end{array}$ & $\begin{array}{c}\mathrm{W}_{\text {Out }} \\
(\mathrm{MeV})\end{array}$ & $\begin{array}{c}\mathrm{ZT}^{2} \\
(\mathrm{M} \Omega / \mathrm{m})\end{array}$ & $\begin{array}{c}\mathrm{P}_{\text {Cavity }} \\
(\mathrm{MW})\end{array}$ & $\begin{array}{c}\mathrm{P}_{\text {Beam }} \\
(\mathrm{MW})\end{array}$ & $\begin{array}{c}\mathrm{P}_{\text {Total }} \\
(\mathrm{MW})\end{array}$ & $\begin{array}{c}\mathrm{E}_{0} \mathrm{~T} \\
(\mathrm{MV} / \mathrm{m})\end{array}$ & $\mathrm{Q}_{0}$ \\
\hline 1 & 59 & 41 & 19 & 4.15 & 43.442 & 7.532 & 28.22 & 0.337 & 0.178 & 0.515 & 1.495 & 35,900 \\
\hline 2 & 47 & 32 & 23 & 6.06 & 43.361 & 22.885 & 45.25 & 1.058 & 0.544 & 1.602 & 2.787 & 40,100 \\
\hline 3 & 33 & 24 & 16 & 6.32 & 45.376 & 39.765 & 43.54 & 1.277 & 0.597 & 1.874 & 2.958 & 43,200 \\
\hline 4 & 27 & 19 & 27 & 6.41 & 45.376 & 56.536 & 41.91 & 1.292 & 0.593 & 1.885 & 2.889 & 42,500 \\
\hline 5 & 23 & 17 & 23 & 6.29 & 45.376 & 72.521 & 40.83 & 1.284 & 0.576 & 1.860 & 2.789 & 43,400 \\
\hline 6 & 21 & 14 & 21 & 6.35 & 45.376 & 86.827 & 39.03 & 1.254 & 0.506 & 1.760 & 2.761 & 43,300 \\
\hline
\end{tabular}

The space for post couplers between a drift tube and the tank wall is $\sim 92.3 \%$ of $\lambda / 4$ at $402.5 \mathrm{MHz}$, an ideal distance for ensuring good stability. The Al model has enough holes to test stabilization with post couplers at every one, two, or three drift tubes. Bead-perturbation measurements (see Figure 2) show that 19 post couplers, one adjacent to every third drift tube, stabilizes the field distribution against the largest expected frequency errors.
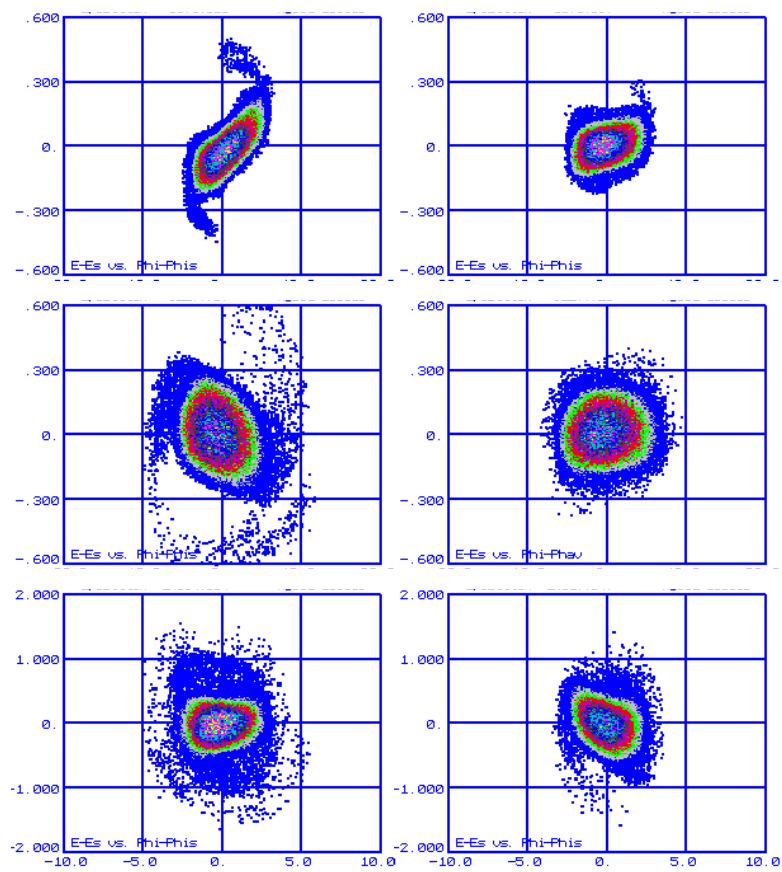

Figure 3. Longitudinal emittance without (left) and with (right) DTL inter-tank matching at end of DTL (top), CCL (middle), and SCL (bottom).

Table 1 lists the DTL design parameters for each tank. Tank diameters $\sim 0.4 \mathrm{~mm}$ larger than the 2D Superfish model correct for the frequency effects of stems, post couplers, and slug tuners. The space between tanks is $1 \beta \lambda$ long. To compensate for the missing longitudinal focusing and transverse defocusing we adjust the synchronous phase $\phi_{\mathrm{s}}$ in nearby gaps. Table 2 lists changes in length applied to the last three and first three cells in each tank that produce a smooth phase advance per unit length across the transition. For example, cells 1, 2 and 3 in tank 2 are $3.79^{\circ}$ longer than $\beta \lambda$, the distance traveled in one rf period. If $\phi_{4}$ is the phase at cell 4 , the first three phases are $\phi_{3}=\phi_{4}-1.89^{\circ}, \phi_{2}=\phi_{4}-5.68^{\circ}$, and $\phi_{1}=\phi_{4}-9.48^{\circ}$. More negative phases increase focusing. The longitudinal phase space plotted in Figure 3 at three locations along the linac shows the importance of the inter-tank matching. The matched-case normalized emittances are $\varepsilon_{\mathrm{T}}=0.0277 \mathrm{~cm}$ $\mathrm{rad}$ and $\varepsilon_{\mathrm{L}}=0.264 \mathrm{keV}-\mathrm{deg}$; for the unmatched case $\varepsilon_{\mathrm{T}}=$ $0.0314 \mathrm{~cm}$-rad and $\varepsilon_{\mathrm{L}}=0.306 \mathrm{keV}-\mathrm{deg}$. The matching also reduces the radial extent of the beam. See Ref 2 for more details of the SNS linac beam dynamics.

Table 2. Cell-length adjustments (degrees).

\begin{tabular}{|l|c|c|}
\hline Interface & Exit $\Delta \phi /$ cell & Entry $\Delta \phi /$ cell \\
\hline Tanks 1-2 & -2.39 & +3.79 \\
\hline Tanks 2-3 & -2.39 & +3.72 \\
\hline Tanks 3-4 & -2.76 & +3.35 \\
\hline Tanks 4-5 & -2.75 & +3.33 \\
\hline Tanks 5-6 & -3.37 & +3.08 \\
\hline Tank 6-CCL & -4.24 & 0.0 \\
\hline
\end{tabular}

\section{COUPLED-CAVITY LINAC}

Above $\beta \sim 0.4$ a conventional $805-\mathrm{MHz} \mathrm{CCL}$ is more efficient than the 402.5-MHz DTL. The introduction of superconducting cavities above $186 \mathrm{MeV}$ reduced the CCL to $\sim 11 \%$ of its previous scope. Table 3 lists the major CCL parameters, which consists of 48 eight-cavity segments divided into four twelve-segment rf modules.

Table 3. CCL Design Summary

\begin{tabular}{|l|l|}
\hline Frequency & $805 \mathrm{MHz}$ \\
\hline Injection, Final Energy & $87,186 \mathrm{MeV}$ \\
\hline Micropulse, Macropulse Current & $52.0,35.4 \mathrm{~mA}$ \\
\hline Average Accelerating Field & $3.7 \mathrm{MV} / \mathrm{m}$ \\
\hline Quadrupole Focusing Lattice & FODO \\
\hline Transverse Focusing Period & $13 \beta \lambda$ \\
\hline Length & $55 \mathrm{~m}$ \\
\hline Radial Aperture & $1.5 \mathrm{~cm}$ \\
\hline Peak Surface Electric Field & $<1.5 \mathrm{Kilpatrick}$ \\
\hline Structure Power & $9.62 \mathrm{MW}$ \\
\hline Beam Power @ 35.4 mA & $3.49 \mathrm{MW}$ \\
\hline No. Modules,Segments,Cavities & $4,48,852$ \\
\hline No. 5-MW Klystrons, Drive Irises & 4,8 \\
\hline
\end{tabular}

A 3-cell bridge coupler spans each $2.5 \beta \lambda$-long intersegment space. Electromagnetic quadrupole magnets (EMQs) and diagnostic elements external to the rf 
structure occupy the intersegment spaces. A transverse focusing period consists of two segments and two drift spaces containing EMQ singlets. In the earlier $1-\mathrm{GeV}$ design, the FODO lattice period was $12 \beta \lambda$ long at 805 MHz. We increased the lattice length to $13 \beta \lambda$ in order to place all the bridge couplers on the same side of the structure. Bridge couplers replace an earlier concept with long coupling cavities between segments. An analysis based upon a coupled-circuit model showed insufficient coupling because of the large volume of these coupling cells.

To simplify the mechanical design 3], we fixed some cavity dimensions for the entire CCL. For example, all accelerating cavities have the same diameter and outer corner radius, which makes all intrasegment coupling cavities identical. Also, all the coupling slots are the same size causing a gradual reduction in cell-to-cell coupling as cavities increase in length. The average magnetic coupling varies from $\sim 5.4 \%$ in module 1 to $\sim 4.6 \%$ in module 4 .

We measured rf properties of aluminum models for the shortest and longest segments. Figure 4 shows a 17-cavity model for $\beta=0.4$ with 8 accelerating cells, 6 intrasegment coupling cells, 2 intersegment coupling cells, and 1 center bridge cell. Within the $\beta=0.4$ segment, the cell-to-cell coupling $\mathrm{k}=5.8 \%$, between an end accelerating cell and a bridge coupling cell $\mathrm{k}=4 \%$, and between the center bridge cell and the bridge coupling cells $\mathrm{k}=7 \%$. This difference in $\mathrm{k}$ on either side of the bridge coupling cells reduces the center-bridge-cell power to $\sim 60 \%$ of the accelerating-cell power. The second nearest neighbor coupling (between adjacent accelerating cells) lowers the $\pi / 2$ mode frequency relative to the average accelerating cell frequency. The coupling $\mathrm{k}_{2}=$ $1.1 \%$ in segment 1 and $\mathrm{k}_{2}=0.87 \%$ in segment 48 . Target frequencies of the accelerating cells are 809.8 and 808.3 $\mathrm{MHz}$ for segments 1 and 48 .

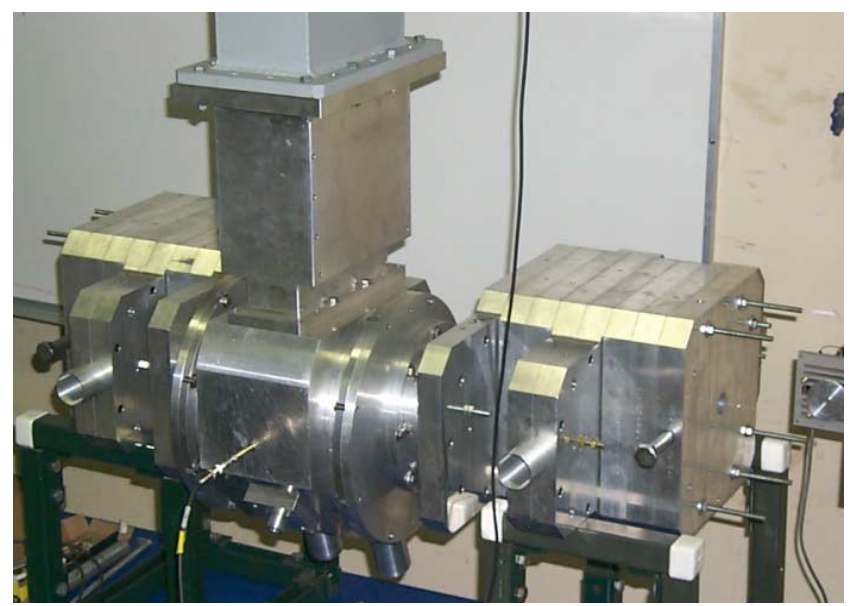

Figure 4. CCL aluminum model of bridge coupler between two 4-cavity segments and connected to the wavegude.

The center bridge cell length varies from $23.2 \mathrm{~cm}$ to $36.8 \mathrm{~cm}$ over the length of the CCL. The coupling slots on the ends of this cavity tend to lower the frequency of a $\mathrm{TE}_{111}$ mode leading to a field instability. A tuning post at the azimuthal location of the opposing slots and centered longitudinally moves the TE mode to well below $700 \mathrm{MHz}$ where it does not affect the TM pass band appreciably. Figure 5 shows axial bead-perturbation measurements of the tilt sensitivity with and without the tuning post. These data are cell by cell field differences for the 8 accelerating cavities with deliberately detuned end accelerating cells. A $-1.5-\mathrm{MHz}$ frequency error in the coupling cavity between cell 3 and cell 4 caused the small dip at cell 4 for both measurements.

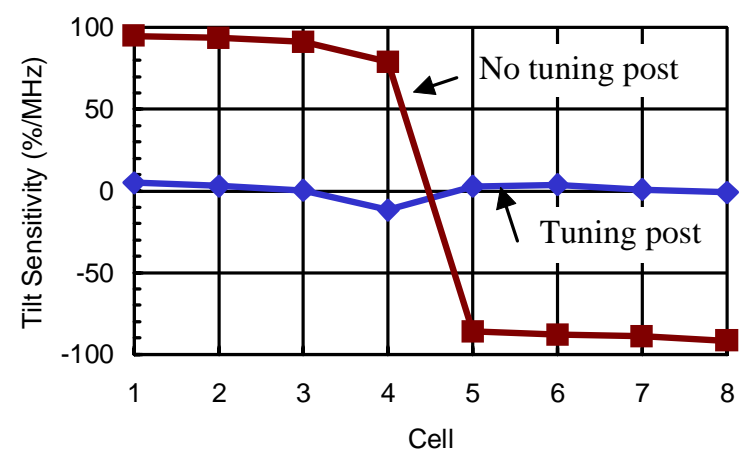

Figure 5. Tilt sensitivity with TE-mode tuning post.

\section{CONCLUSION}

We have outlined the design of the SNS roomtemperature linac. Power densities are manageable and surface electric fields are conservative. Low-power DTL and CCL model measurements have been essential to verify rf cavity design and provide details for some of the cavity dimensions. Before fabrication of the copper CCL structures begins, we will have another opportunity to tune the "hot model" during the summer of 2001. The hot model consists of two full brazed segments and a bridge coupler.

\section{REFERENCES}

1 J. H. Billen, H. Takeda, and T. S. Bhatia, "Linac RF Structures for the Spallation Neutron Source," Proceedings of the 1999 Particle Accelerator Conference, p. 3585 (March 27 - April 2, 1999).

2 J. Stovall. J. Billen, K. Crandall, S. Nath, H. Takeda, R. Shafer, and L. Young, "Expected Beam Performance of the SNS Linac," this conference.

3 N. Bultman, "Mechanical Design of the SNS Coupled Cavity Linac," this conference. 